\title{
Innovative public goods production and organizational form selection: a case study of the Wenzhou Private Lending Service Center
}

Jinglin Xiang ${ }^{1}$ and Xiang Zhang ${ }^{2^{*}}$

\section{* Correspondence:} xiangzhang@zju.edu.cn

${ }^{2}$ School of Public Affairs, Zhejiang University, 388\# Yuhangtang Road, Xihu District, Hangzhou, Zhejiang Province 310058, China

Full list of author information is available at the end of the article

\begin{abstract}
This article discusses innovative public goods production and organizational form selection based on a case study of the Wenzhou Private Lending Service Center, which was founded during Wenzhou's comprehensive financial reform in 2012. We find that the local government granted a company the authority to manage the private lending registration system, which was a new type of public good. However, the company presented certain organizational characteristics of government departments in the production of public goods. Our study suggests that the production of innovative public goods is influenced by an uncertain technical environment or uncertain institutional environment. Local governments will try to reduce possible loss due to high uncertainty from both environments, an important strategy of which is choosing the organizational form that can reduce the risk in production and grasping the control rights of the operation of the organization. This article provides an analytical model for organizational form selection in a multidimensional environment.
\end{abstract}

Keywords: Innovative public goods production, Technical environment, Institutional environment, Uncertainty, Organizational form selection

\section{Background}

In 2011, the breakout of the Wenzhou lending crisis drew the public's attention to "runaway" enterprise owners in Wenzhou. On March 28, 2012, an executive meeting of the State Council established pilot areas for Wenzhou's financial comprehensive reform and approved "the plan of Wenzhou, Zhejiang Province comprehensive financial pilot reform." This plan defined 12 main tasks of the Wenzhou comprehensive financial reform, one of which was "normalizing development of private financing, setting regulations for the management of the private financing, setting up a registration and record system for private lending, and establishing a sound monitoring system for private lending."

On April 26, 2012, an important part of the pilot financial reform was established, the Center (later renamed the Wenzhou Private Lending Service Center, hereinafter "the service center"). With an initial registration asset of 6 million yuan, the service 
center operated as a form of corporation that was jointly founded by 14 private enterprises and 8 natural legal persons. Services provided by the center include information registration, information consultation, information publication, and financial docking services. The service center acts as a platform to attract the supply and demand sides of private lending to engage in trade, in which various financing intermediary service agencies provide services including transaction-brokered contracts, notary, appraisal of assets, legal advice, and other services for both sides. The service center itself provides registration services for signed loan contracts.

After the service center was established, many other cities in China set up similar private lending service centers. ${ }^{1}$ Interestingly, although there are differences in the internal structure of these service centers in different cities, they share a high level of similarity in their organizational form-almost all local governments choose to operate the centers as a form of corporation. What is more, these service centers are registered as corporations in nature but are more similar to government departments in the aspects of their name and actual operation.

As an innovative management system for regulating private financing, private lending registration bears typical properties of public goods. ${ }^{2}$ Theoretically, the government generally produces this type of public good. Why then do local governments choose enterprises to produce these public goods? Why do corporations present certain organizational characteristics of government departments in the production of public goods? What leads local governments to choose this model of production, and what is the underlying rationale behind this particular model? The remainder of this article discusses these questions.

\section{Existing explanations and analytical models}

Existing research argues that under certain conditions public goods can be produced by the private sector (Demsetz 1970; Coase 1974; Goldin 1977). However, it should be noted that provision and production refer to two distinct practices (Musgrave 1959; Ostrom et al. 1961). A goods provider takes the role of financing, leading, planning, and monitoring, while a goods producer is mainly involved in direct production. The goods provider and goods producer can either be from the same body or different bodies. In the model of public goods production described above, the government is the provider while an enterprise is the producer. Why did the government choose to make an enterprise the producer rather than taking on this role itself?

\section{Supply efficiency theory}

One explanation to the above question comes from the supply efficiency theory, which claims that the government makes the decision about whether to be a provider or a producer based on a comparison of which has the higher supply efficiency. Transaction cost economics (Coase 1937; Williamson 1979) claims the selection of provider or producer depends on the transaction costs of the two practices. Savas (2002) points out that provision and production by the same body generates a bureaucratic cost, that is, the cost of maintaining and managing a bureaucratic system; provision and production by different bodies generates a transaction cost, that is, the cost of hiring and supervising an independent producer. He argues that a comparison of the 
cost between these two models will decide whether provision and production should be separated. However, the new property rights economics (Grossman and Hart 1986; Hart and Moore 1990) argues that under the condition of an incomplete contract, the two contracts refer to different arrangements for residual control rights, which generate different modes of incentive. The selection of provision or production is thus a question of which contract has better production efficiency. This theory has been used to analyze the comparative advantage of provision and production by the government under a dual-target condition (improving quality and cost saving): if the government prioritizes the quality of public services, then government production is more efficient than private production; if the government prioritizes cost savings, then private production has a higher efficiency than government production (Hart et al. 1997).

Supply efficiency theory cannot fully explain the question posed at the beginning of this article. First, supply efficiency theory assumes that the efficiency of the different modes of supply is comparable. However, in the case of a private lending registration system, such a comparison is not feasible since the new private lending registration system is a newly created public good, and thus, information about transaction costs and production efficiency for different modes of provision and production is lacking. Second, supply efficiency theory cannot explain why the corporation presents certain organizational characteristics of government departments in the production of public goods. Third, supply efficiency theory does not pay enough attention to the environmental factors that affect governmental behavior. As a matter of fact, many environmental factors in the field of private lending have important influences on the government's selection of provision or production models.

\section{Political risk theory}

An alternative explanation to the Chinese government choosing private organizations for the production of public goods is the theory of political risk of centralization (Fei 2009; Cai 2008; Cao 2011; Cao and Zhou 2013; Cao and Luo 2013). It argues that a high level of concentration of political power will produce high political risk; a common approach to reducing political risk is to vertically decentralize administrative duties, namely from the central government to the local government (decentralization to local) and from the local government to society (decentralization to society). In this sense, the practice in which the government grants enterprises the right to produce public goods is in fact a kind of vertical decentralization.

Political risk theory provides insightful explanations to the governing mechanism of the Chinese government, but these are still not enough to answer the questions raised by this article. First, political risk theory aims to address state-society relations and thus assumes that the state prioritizes social stability. This assumption determines that political risk theory is mainly concerned about the social environment when addressing governing issues, rather than other types of environments that the government also needs to address, such as the legal environment for the production of public goods. Second, political risk theory also fails to explain why the corporation presents certain organizational characteristics of government departments in the production of public goods. Third, political risk theory does not discuss the specific 
procedures of the production of public goods in the condition of vertical decentralization and thus ignores the analysis of interactions between the government and other relevant organizations.

\section{Analytical model}

Given the limitations of the two kinds of interpretation logic discussed above, this article uses analytical perspectives from organizational sociology to address the question about governmental behavior in reaction to the external environment in order to explain both the external organizational characteristics and the internal operational mechanisms of the service center. We argue that governmental selection of direct or private production of public goods is subject to the technical environment and the institutional environment. Regarding production of innovative public goods, high uncertainty in the technical or institutional environment will make the local government take measures to reduce possible loss, one important strategy of which is choosing the organizational form that can reduce the risk of those two constraints on production and to grasp the control rights of the organization's operation. ${ }^{3}$

\section{An uncertain technical environment and institutional environment}

Production of public goods is constrained by the technical environment and the institutional environment (Meyer and Rowan 1977; Scott and Meyer 1991; Scott 1991; Powell 1991). Constraints from the technical environment include the request for improving production efficiency and service quality, fluctuations in market demand, and availability of resources and means of production. Constraints from the institutional environment are legitimacy requirements about organizational structure and procedures for production.

Uncertainty is a key feature of the organizational environment, and an uncertain technical or institutional environment has significant influences on the organizational structure and behavior. The private lending registration system discussed in this article is a new type of public good, and such public goods production is more likely to be constrained by an uncertain environment. However, classic explanations about organizational behavior in an uncertain environment fail to fully explain the aforementioned phenomena. ${ }^{4}$ For this reason, we need a suitable concept to understand the particular organizational strategy utilized in response to environmental uncertainty.

\section{Selection of organizational form}

A technical environment and institutional environment with high uncertainty produce a high level of risk (the uncertainty of loss) in the production of public goods. The government tends to choose various strategies to reduce this high risk, one of which is the selection of organizational form. Organizational form is a classic concept in the study of organizations. Interpretations of the concept vary according to different theoretical perspectives. Organizational economics views organizational form as a power allocation method or governance structure for coordinating the relationship between subjects of different interests (Chandler 1962; Williamson 1975, 1985; Milgrom and Roberts 1992; Aghion and Tirole 1995; Maskin et al. 2000; Qian et al. 2006). From the perspective of organizational ecology, organizational form is an action blueprint for carrying out 
production activities, the key features that can be used to distinguish different organizational entities or populations including formal structure, operation mode, and normative order of the organization (Hannan and Freeman 1977, 1986; Romanelli 1991; Ruef 2000). However, the two abovementioned definitions both emphasize the internal structure of organizations; they are not able to explain complex external organizational characteristics and the subtle association between the internal structure and the external characteristics we have observed.

Given the limitations of the two theoretical definitions, we used Tian's (2004) definition by which organizational form is an open and written illustration about the "official organizational name, its purpose, property, formal structure, operational mode and organizational rules that organizations provide to other relevant organizations (including regulatory bodies and the general public). ${ }^{5}$ This definition emphasizes three characteristics of organizational form. The first feature is externality. Just like the face of an organization, organizational form is the appearance that organizations present to the external environment. This means organizational form is the communication media that has symbolic significance between an organization and the environment. The second feature of organizational form is stability; that is, the combination mode of different elements (such as names, properties, and targets) of an organizational form has a high level of stability. The third feature is plasticity, which refers to the idea that organizational form can occur and maintain deformation when organizations are under external environment pressure. This kind of deformation can occur in a specific element of a certain organizational dimension or in the combination mode of certain elements of different organizational dimensions. All these deformations are relevant to organizations' rational choices under external environment pressure.

In this article, this so-called organizational form selection refers to an organization's selection of an organizational form or a combination of different organizational forms among all available choices in order to reduce the risk constraints from external environments. The reason organizational form selection is helpful in reducing these risk constraints lies in the fact that the risks that different organizational forms face vary in their properties and degrees. For example, some risks may be associated only with certain types of organizational forms but not with other types, and the same risks may have different degrees of impact on different organizational forms. In other words, different organizational forms have their own comparative advantages in reducing different risks. This particular feature provides an important strategy for the survival and development of organizations in uncertain environments; organizations can thus compare and choose among available organizational forms to maximally reduce risks due to the uncertainty of environments.

We categorize risks that organizations face into two types; one comes from the technical environment (technical risk) and the other from the institutional environment (institutional risk) (shown in Fig. 1). In a set of available organizational forms, A refers to an organizational form with both high technical and institutional risk, B refers to an organizational form with high technical risk but low institutional risk, $\mathrm{C}$ refers to an organizational form with low technical risk and high institutional risk, and D indicates an organizational form with both low technical and institutional risk. Organizations choose among the four available options in order to minimize risks. 


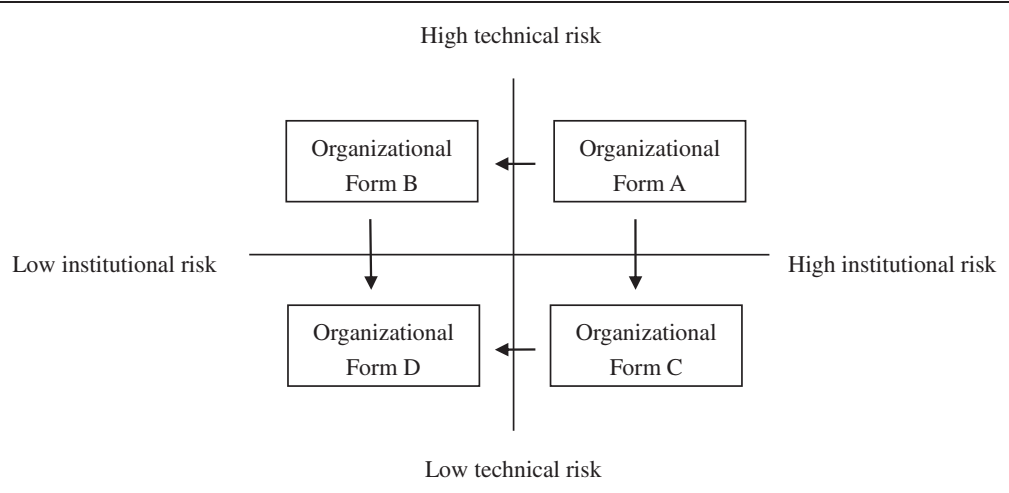

Fig. 1 Risk constraint and organizational form

Appling this analytical model to the production of public goods, if only from a lower risk perspective, the government would naturally prefer organizational form D. However, reality is more complex than the theory explained here. It may be that organizational form D is not available; another possibility is that even if all four organizational forms are available the selection of organizational form $\mathrm{D}$ is constrained by other factors. Under such conditions, the government may select organizational form $\mathrm{B}$ or $\mathrm{C}$ or combine $\mathrm{B}$ and $\mathrm{C}$ to create a new hybrid organizational form. From this perspective, the hybrid organizational characteristics of the service center studied in this article were caused by the government combining elements from the organizational form of an enterprise and the organizational form of government departments (such as property of enterprise and name of government departments). The rationale behind it was the local government's intent to maximally reduce both technical and institutional risks.

\section{Distribution of control rights}

Organizational form and organizational operation (Tian 2004) are not necessarily associated; rather, they are often decoupled (Meyer and Rowan 1977). If organizational form is the appearance that organizations present to external environments, organizational operation then contains the real action logic of the organization. In particular, when a hybrid organizational form appears, only through organizational operation is one able to understand organizational behavior in depth. In the case of the government authorizing enterprises to undertake the production of public goods, one key criterion to assessing organizational operation is the distribution of actual control rights, that is, how decision-making rights are distributed between the government and the enterprise.

Despite the new property rights economics claims that residual control rights are often granted to asset owners under the condition of incomplete contracts (Grossman and Hart 1986; Hart and Moore 1990), in real life, the actual distribution of control rights tends to be more complex. Aghion and Tirole's (1997) research about organizations' internal formal authority and real authority provides useful insights. They point out that due to information asymmetry the agent often possesses the real decisionmaking authority, and although the principal is the decision-making party, he actually possesses the formal authority. What is more, the agent's real authority undermines the 
principal's formal authority to a certain extent. In this case, in order to reduce information asymmetry, the principal tends to strengthen supervision over the agent. However, this supervision generates extra cost for the principal, and thus, the principal must balance the costs of supervision and the benefits of control rights.

In the production of innovative public goods, the contract between the government and the enterprise is highly incomplete. Once the government chooses an enterprise to produce public goods, the enterprise possesses an information advantage, thus undermining the government's control rights over the production of public goods to some extent. Therefore, when the government deems the benefit of these control rights to be higher than its cost, it competes to obtain the control rights. Zhou and Lian (2012) specify the control rights associated with internal organizational operation as goal-setting rights, assessing and censoring rights, and incentive distribution rights. Their study suggests that through adjustment of the distribution of assessing and censoring rights, the principal can reduce the real authority held by the agent due to the information advantage. This further highlights the government's grasp of assessing and censoring rights in the actual production of public goods. From this perspective, we can observe the micromechanisms through which the government intervenes in and controls the operation of the organization.

\section{Methods}

This article uses the Wenzhou Private Lending Registration Service Center as a case to discuss the selection of organizational form for the production of innovative public goods. One of the authors of this article participated in drafting the Wenzhou Private Lending Registration Service Center's pilot program (detailed description below), which provided an opportunity to closely observe the decision-making process regarding the construction of the service center, as well as the mechanism of governmental intervention in the process. After the service center had been established, we were commissioned by the local government to study risk management and control and to draft regulatory rules for the service center. ${ }^{6}$ This involvement in these commissions allowed further observation of the service center's operational process. By the end of February 2014, we had carried out nearly 3 months of participatory observation; in addition, we collected data from in-depth interviews and focus group studies.

The author's opportunity to participate in the Wenzhou Private Lending Registration Service Center's pilot program was due to his participation in an earlier project, the "financial innovation research in Q City (a subordinate county-level city of Wenzhou) in Zhejiang Province" in July 2009. This research found that county-level governments had very limited power to reform the local financial system; market access reform and the reform of interest rate marketization in the banking sector had to be approved by the central government. What is more, civil lending behavior was limited to individual lending at that time, and most of the individual lending occurred between relatives and friends. In individual lending, the volume of loans was often constrained. After analyzing the above results, the research team suggested that direct lending between strangers via local governments could be an innovative move for local financial systems. Direct lending transactions between strangers require intermediaries; however, relevant law strictly forbids an unregistered private depository institution from providing deposit and lending services. Then is it possible to develop 
an intermediary service for direct lending without participating in a deposit and lending transaction?

An investigation was carried out to assess the possibility of developing such a practice. The research group found that at that time there was an established business model for lending between strangers, often referred to as the "P2P" model. ${ }^{7}$ The main characteristic of this model is that the intermediary does not participate in the deposit and lending service but provides information, credit assessment, and transaction services for individual lending. Is this practice legal? Can the risks associated with this business model be controlled? Which department is responsible for regulating this service? All these questions had yet to be clearly answered.

The research team thus suggested that the local government of Q City build a unified platform for a variety of private lending brokers; these brokers could use this platform to provide intermediary services, including brokering deals, contract notarization, and consulting for civil lending. The research team also suggested that at the same time the local government should provide registration service for private lending contracts and monitor civil lending. The platform was named the "private financial transactions registration center." After consulting with the local government and experts in finance, the research team submitted a feasibility report on the suggested platform to financial officials of Q City in early November 2009. In this feasibility report, the research team stated that the service center needed to address two questions: how to promote private lending and how to monitor the transaction. Some suggestions were made accordingly in the report.

In addition, the report proposed four types of organizational forms for the service center: "government-affiliated institution," "social group," "state-owned enterprise (SOE)," and "private enterprise." In comparison to the other three organizational forms, the government-affiliated institution type of service center may have the highest credibility, especially for the supply party of the transaction. However, in the event of a dispute between two parties in the transaction, the government would necessarily be involved in resolving disputes had the service center been run as a governmentaffiliated institution. This was the problem that most concerned the government of Q City. What is more, the establishment of a government-affiliated institution had to face the constraints of the Bianzhi system (a staffing regulation system). In January 2010, the Q City financial office was informed that in the short term it could not set up the service center as a government-affiliated institution.

In comparison to a "government-affiliated institution" type, the "social group" type may act as a buffering layer for the government in the event of private lending disputes. However, this type of service center has lower credibility, in particular for the supply side of the transaction. In addition, if the civil association type was chosen, there could be risks regarding the management of transaction data. In January 2010, the Department of Civil Affairs of Zhejiang Province informed the research team that the service center would be a profit-oriented organization and thus could not be registered as a "social group." After carefully considering the credibility of the demand and supply sides of private lending transactions, potential liability for the government, and other barriers, in January 2010, the Q City government decided to grant a local government-owned enterprise the rights to run the service center and register it as an SOE. However, for various reasons, the service center at Q City was not able to open for business for a fairly long time. 
In the second half of 2011, "runaway" local business owners who abandoned their businesses and moved out of the local city became a major issue in Wenzhou city. One particular case, that of the runaway local "spectacles king," Hu Fulin, that occurred on September 20, 2011, drew national attention to the financial crisis in Wenzhou. The Wenzhou city government had already begun to resolve the aftermath of the private financial crisis and started applying to the State Council to build a pilot area for comprehensive financial reform. In early September 2011, Professor Yao XianGuo, member of the advisory board of Wenzhou city and Zhejiang province and leader of the Q City financial innovation research group, once again proposed building a service center for Wenzhou city and Zhenjiang province and submitted a modified blueprint of the service center. His proposal was subsequently written in the pilot program for consideration by Zhejiang province and the State Council.

In November 2011, one author of this article was invited to discuss the plan for constructing the service center with the Wenzhou Lucheng district government. Before the discussion, the Wenzhou Lucheng district had been chosen to run the pilot private lending service center. During the discussion, the author introduced the topic of construction of the service center in Q City and the pros and cons of the four organizational forms of the service center. The Lucheng district government favored a private enterprise type.

On April 26, 2012, the service center, jointly built by 14 member organizations of the Lucheng Industrial and Commercial Association and 8 natural persons, officially opened for business. Interestingly, the enterprise was named the "Wenzhou Private Lending Registration Service Center." 9 The organization of the service center is jointly run by the local government and a local enterprise (Fig. 2) that is under the control of the Wenzhou city government and the Lucheng district government. The Wenzhou Private Lending Registration Services Limited Company was founded to operate the service center. The service center invited P2P financial information service agents and other related ancillary service agents into the service center and invited supply and demand parties in private lending for potential deals. The service center does not engage in the intermediary business; rather, it serves as a platform for intermediary agents and related ancillary service agents and provides private lending registration services. The intermediary agents provide supply and demand parties with services that include credit assessment, motor

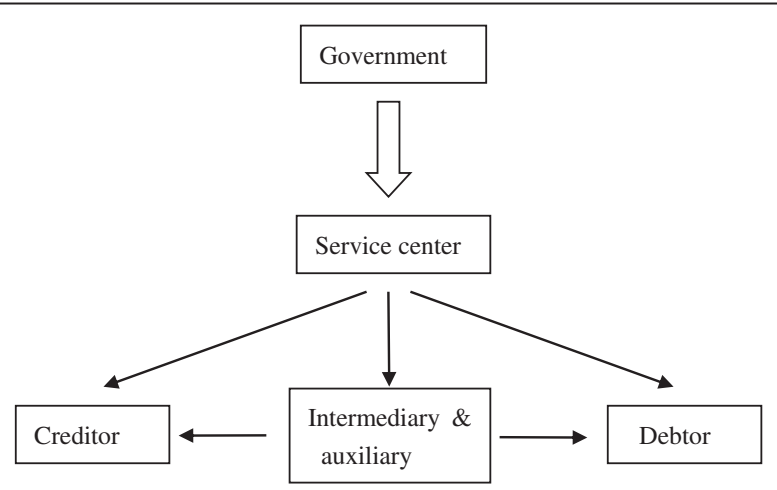

Fig. 2 Organizational model of the service center 
vehicle security check-in kiosks, notaries, secured companies, and insurance companies; law firms provide services that include letters of inquiry, mortgage registration, notarization, and consultation regarding insurance and legal advice. ${ }^{10}$ The service center has received a great deal of support from external administrative resources.

The organization and operation of the service center present complex organizational characteristics. In terms of organizational property, the service center is indeed a registered enterprise, but in its name and its capability of mobilizing resources, the service center is more like a government department or a government-affiliated institution. In particular, it is different from what was proposed in the blueprint for the service center. There is no "appropriate corporate name" added to its name; in addition, it has access to and adopted the credit system of the People's Bank of China, motor vehicle security check-in kiosks, and other resources that general businesses often find no way to obtain (Table 1).

With this in mind, we need to answer the following three questions: why does the government allow an enterprise to produce innovative public goods in a civil lending registration? Why does corporate production of the public goods present certain organizational characteristics of government departments? Who controls the actual operation of the service center-the local government or the local enterprise?

\section{Results}

\section{Why does the government allow an enterprise to produce innovative public goods?}

We argue that the government's selection of producing public goods in a form of a corporation is constrained by the external institutional environment. As an innovative public good, private lending registration involves not only financial legislation in the field of civil finance legislation but also social awareness of the parties participating in the transaction. The top-down legal constraints and the bottom-up social awareness

Table 1 Public sectors and their relevant services at the service center

\begin{tabular}{ll}
\hline Public sector & Relevant services \\
\hline People's Bank of China & Inquiry on the personal credit record in the PBC personal credit \\
& query system. The service center is the first nonbanking institution \\
& which provides this service in China. \\
& Vehicle/automobile mortgage business in private lending can be \\
directly registered at the service center with the special line from & the Wenzhou Vehicle Administrative. \\
Vehicle Administrative & For private lending with equity mortgages, intellectual property \\
rights mortgages, and device mortgages; these can be directly \\
registered with the Industrial and Commercial Bureau.
\end{tabular}


have created two essential institutional environments for the local government, and the potential risk in the two environments has a major influence on the government's selection of the organizational form for the service center.

\section{The legal risk: the top-down institutional environment}

It has been acknowledged that with the national administrative reform and the increase in the rationality of the administrative system (Zhang 2001; Qu et al. 2009; Lv 2013), legalization, technology, and standardization have gradually become important issues for the development of the administrative system, and legal constraints have become even stronger for local governments. In order to pursue a better political future, local government officials have had to balance system incentives (Zhou 2004, 2007; Rong et al. 1998) and legal constraints (Mao 2005; Wang and Wang 2009) in order to improve their political performance, that is, not only improve efficiency but also control liability risks. That is why local governments focus on both supply efficiency and legitimacy of governmental behavior in order to avoid legal risks.

(1) The lack of laws. The private finance business in China has long been a legal gray area. There is a lack of a good legal and regulatory system or a clear regulatory department for this type of business. ${ }^{11}$ In particular, there is no clear legal system or regulatory department to monitor newly invented civil lending services which are registered as "Economic Information Consulting Co., Ltd." or "Investment Management Co., Ltd."

Before the launch of relevant laws and regulations, there were no laws or regulations to guide a local government in setting up its own center, introducing broker institutions for private lending, and providing registration service. However, if such an intermediary role was undertaken by an enterprise, it would be regarded as contractual relations in a market. This helps to prevent direct contact between private lending and the government, thus reducing the government's legal risk. For this reason, the district government chose enterprises to produce public goods and, in the meantime, strongly promoted the introduction of relevant regulations for the service center. As one regional financial officer observed:

Regarding the organizational model of the service center, in terms of the legal perspective although many functions of government are subject to particular laws or regulations there is no such law or regulation for running the service center and thus the leadership in the government decided to allow the market to provide such services. ... The government's behavior must be supported by law, and if you look at information and consulting companies they are in a gray area; there is no legal system to regulate this sector. It is thus better for enterprises to run this type of business because it is regarded as market behavior, and there is no authority responsible for regulating their operation.... The provincial government has long been drafting the "Wenzhou private lending regulation,"12 and when it comes out we [the government] will use it to provide private lending registration. (Interview record 20130130)

(2) Legal friction. The establishment of a private lending registration system also faces certain challenges from the legal system; one typical challenge comes from 
tax regulation. ${ }^{13}$ In civil lending, creditors usually pay no tax for interest on loans. However, once the transaction is registered with the service center, the interest must be taxed. If the government requires taxing on interest, it greatly decreases the incentive for private lending to use the service; if the government does not tax the interest, then it will violate relevant tax regulations. In response to this dilemma, a rational choice of the government is to alter the organizational form of the service center in order to circumvent the tax regulation. Below is a quote from an official of a district financial office:

Although this is a part of the financial reform, if certain laws or regulations are not altered accordingly then we cannot ignore those legal constraints. ... At that time what worried me most was in fact the question of taxation; the taxation should follow the state's law! The tax law requires the government to tax on behalf of the state. If the government runs the service center, then should I deduct the tax or not? Once the private lending transaction is registered at the center, I have all of the relevant data. It would be fine if the tax bureau does not check, but if it checks how should I respond? Should I show them the record? If they found out that we did the tax deduction, then it would be the government's liability. If an enterprise provides the registration service the law requires you to voluntarily declare this information, so if you do not declare then it is your own responsibility and has nothing to do with government. It was really a big problem at the time, and we could do nothing. (Interview record 20130620)

(3) Uncertainty associated with the implementation of the law. Although in the financial area basic legal provisions for civil financial activities have created many constraints for such activities, many of these legal provisions are not clear enough. ${ }^{14}$ Under such conditions, there is a very vague line between legal and illegal private financial activities, which causes great uncertainty for the implementation of the law. Under such circumstances, there is a high legal risk for the government to regulate civil financing. The local government tends to feel some civil financial activities may be judged illegal in court rulings when there is a dispute, which makes it difficult for the local government to avoid responsibility. In the case discussed here, the government would face a high legal risk if it owned and ran the service center.

\section{Social risk: a bottom-up institutional environment}

As pointed out in a study by Cao and Zhou (2013), the government's production of public goods may face certain social challenges. For one thing, in producing public goods, the local government may threaten certain public interests or accepted social norms, which could cause public discontent and protest. Additionally, the increasing awareness of interest of the policy object ( $\operatorname{lv} 2013$ ) together with the strategic use of petition, complaints, and other social protests has become an important institutional environment for the local government and created constraints for the local government's legitimacy. Therefore, the central government has emphasized social harmony, and local governments tend to be very sensitive to any potential social risk. 
There are many potential risks in private lending, in particular the borrower default risk. In the circumstance in which the government runs the service center, once there is a case of borrower default the victim in the case may request that the government pay for liability. If the victim is dissatisfied with the government's resolution, an petition or protest can be used. Taking this possibility into consideration, the district government in the case chose an enterprise to undertake the production of public goods. One leader of the government stated: "To be frank, we in the government are also afraid of undertaking this business because whether in Wenzhou or any other place when there is an accident the public usually blames the government, a specific situation that is habit for the civil society. If the government is going to run the service center, it is very difficult to gauge the degree of risks. In addition, there is concern about social harmony; we have to take a lot into consideration (Interview record, 20130130)."

It should be noted that the government faces social risks in both direct and indirect regulation of the service center. The main difference between the two models is that indirect regulation can reduce the government's social risk relatively. For the case here, in which the government promoted the establishment of the service center, the public may still require the government to be liable for risks associated with transactions. However, the role that the government plays here is more like a monitor and coordinator, and thus, the public cannot assume the government holds direct responsibility for potential risks. Therefore, the government faces a lower degree of social risk when indirectly running the service center.

\section{Selection of private enterprise}

Facing multiple risks, the government would not set up and operate the service center by itself. Why then would the government choose private enterprises to run the service center? One official at the district financial office stated that while the privately run nonenterprise form, $\mathrm{SOE}$, and private enterprise can all reduce risks for the government, the selection of a particular form is also influenced by other constraints.

We discussed with leaders for a long time and were mainly considering a private nonprofit organization, but a private nonprofit organization is normally registered as a public service organization, which is not allowed to undertake financial business. We then negotiated with the Bureau of Civil Affairs but we couldn't find a solution. The remaining choices were an SOE or a private enterprise, but there were no suitable SOEs in our district that could undertake such business. Therefore we decided to choose a financially successful private enterprise. Choosing a private enterprise meant that we also needed to think about the government's role in the operation of the service center. Though a private enterprise is profit oriented, it should be in accordance with our original plan for the service center. However, an enterprise is a market actor and we needed to take this into account, so it was very complex situation. Later on we thought about the local Industrial and Commercial Union. After all, the Industrial and Commercial Union serves as a bridge between the government and civil society, and thus we could have influence on it. In addition, the 
chair of the union in our district, $\mathrm{Mr}$. Li, is a very respectable entrepreneur.

Hence we asked Mr. Li to initiate the construction of the service center. He had our plan and we asked them to make their own decisions as to how to build the center. Later a new enterprise with twenty-two vice-chairmen of the union was founded. (Interview record 20130130)

It can be seen that in both conditions, a private enterprise is the organizational form that can largely reduce the institutional risks faced by the government. The government's selection of a private enterprise also involved careful consideration. Eventually, the government selected the Industrial and Commercial Union to found a new enterprise to operate the service center, which signaled the union's political significance. Han (2004) argues that the Industrial and Commercial Union acts as a "double agent" between the government and civil society. This dual role gives the industrial and commercial union strong organizational flexibility so that it can switch its role between public and private agent depending on the situation. The dual role allows the district government to balance the production of public goods by a private enterprise and governmental control of the service center.

\section{Why does corporate production of the public goods present certain organizational characteristics of government departments?}

We argue that the corporate production of public goods presents certain organizational characteristics of government departments due to the government's rational choice in dealing with constraints from the technical environment. This constraint refers to market risk, i.e., whether the service center as a type of innovative public good had a market when the civil trust system was hit hard in the financial crisis. As analyzed above, utilizing a private enterprise can reduce institutional risk for the government, and thus, the government chose to let a private enterprise produce public goods. However, although a private enterprise can reduce institutional risk, it does not have the competitive advantage that allows it to lower market risk. Therefore, the government needed to add bureaucratic elements into the corporate production of public goods.

\section{An enterprise with a government brand}

Although the local government allowed a private enterprise to operate the service center, it did not name the service center as an enterprise but rather the "Wenzhou Private Lending Registration Service Center." In other words, the government defined the service center as a private enterprise but named it with a government brand. One official from the district financial office gave the following reasons:

The original name was the Wenzhou civil lending registration service center; this is because although our center is an enterprise, it is a special type of enterprise that is directed by the local government to provide a private lending registration service. It would mislead the public if the center was called an enterprise, and thus the center was registered as an enterprise but named as a service center. Think about it, why does someone give his personal information to a private enterprise? The government would like to provide such a service but was afraid of failure, so it let the market 
provide the service and grants it credibility by using the name of "service center." Although the center has the nature of an enterprise, most people still think that this is set by the government, otherwise they would not come and register. They choose the service center mainly because of their trust in the government. (Interview record 20140225)

The name "Wenzhou Private Lending Registration Service Center" indicates higher credibility, which helps to produce more private lending transactions and registrations. In fact, this uses government credit as a signal (Zhang 2010) to reduce information asymmetry between the supply side and demand side of private lending. The service center was founded in the context of financial crises; if it used an enterprise's name, it would be difficult to gain the trust of the market. In contrast, a government brand is an effective signal (Spence 1973) that has the comparative advantage of lowering market risk.

\section{Resources that are difficult for an enterprise to mobilize}

In addition to the credibility given by the name of the service center, the service center still needed to obtain a comparative advantage in terms of financial security, standardization of procedure, and transaction convenience in order to promote private lending transactions. In the context of high information asymmetry, the service center needed to show its mode of operation and its capacity for preventing transaction risk and increasing transaction efficiency to both the demander and supplier in private lending, especially the supplier.

Established in the context of the financial crisis, the service center would also have little market confidence if it functioned the same as a private enterprise, that is, relying on intermediary agents to proceed with transactions and prevent potential risk. In contrast, a government-led mobilization of resources is conducive to improving risk prevention, control capacity, and operational efficiency. In terms of risk management and control, the resources mobilized by the government include pretransaction risk control and posttransaction risk disposal, mainly in the forms of the credit query system of the People's Bank of China as well as express service by the People's Courts. In terms of transaction efficiency, the resources mainly include public notaries, vehicle mortgage registration service, and services from the Housing Management Bureau, Industrial and Commercial Bureau, and other public sectors.

There is no doubt that government-led resource mobilization is an effective signal (Spence 1973) that helps the service center obtain trust from both the demander and supplier in private lending. It is effective because this mobilization can provide the service center with a high capability of risk control and transaction efficiency, which ordinary intermediary agents cannot obtain. It also involves a larger scale of resource mobilization, and the resources the service center obtains are of better quality. In terms of scale of resource mobilization, there are many administrative bodies that support the function of the service center, which creates a "resource-intensive" project (Zhou 2005). In terms of resource quality, rare resources such as the credit query system of the People's Bank of China are provided. In short, the bureaucratic features of the service center are the results of governmental rational choice that aims to reduce the service center's market risk. 


\section{Government control of corporate production of public goods}

As analyzed earlier in this article, when the government chooses to let a private enterprise produce public goods, it faces information asymmetry that could weaken its control over the production process. However, if the government deems the returns of investment in obtaining control rights are higher than the cost, then it will compete for the control rights. Thus, even though the government chooses corporate production of public goods, this does not necessarily mean that enterprises obtain the actual control rights.

Before analyzing how the government obtains the actual control rights, it is necessary to discuss why the government competes for the control rights. It needs to be pointed out that the service center is part of the pilot project for financial reform in Wenzhou, and Lucheng district is responsible for the service center pilot project. Thus, the development of this service center would be evaluated as part of the district government's political performance. There are many potential risks associated with private lending, and if these risks occur, the service center and the district government would not be able to resolve them. Thus, the district government has to strengthen its monitoring and control of the service center in order to prevent risks. The monitoring includes not only post-event supervision but also pre-event and mid-event supervision. The following part analyzes the distribution of control rights between the government and private enterprise via the government's monitoring policy and direct intervention in the service center's operation.

\section{Allocation of control rights in monitoring policy}

On December 12, 2012, the district government issued the "Wenzhou Private Lending Service Center regulation measures (Trial)," which monitored services offered by the service center, intermediary agencies and other ancillary services, and so on. The methods show that although the government allowed a private enterprise to operate the service center, the government maintained close and careful control over the service center's operation. For example, rules made by the private enterprise regarding the operation of the service center as well as the selection of intermediary agencies had to be approved by the government. In addition, the private enterprise had to report all transaction data and information about intermediary agencies to the government. Lastly, the government uses a dynamic monitoring system to assess the operation of the private enterprise. This indicates that the local government rather than the private enterprise holds the actual control rights of the service center.

\section{Allocation of control rights in daily operations}

In addition to the monitoring methods issued by the government, the local government has another method of control in the actual operation of the service center. A typical example is that the local government sets up a supervisory office and assigns a deputy director from the local financial office to take charge of supervising the service center's daily operations. ${ }^{15}$

The administrative structure of the service center consists of the general manager's offices and four other functioning departments (Fig. 3). The general manager is responsible for the overall operation of the service center and has decision-making rights. The department of the general office is responsible for core functions of the 


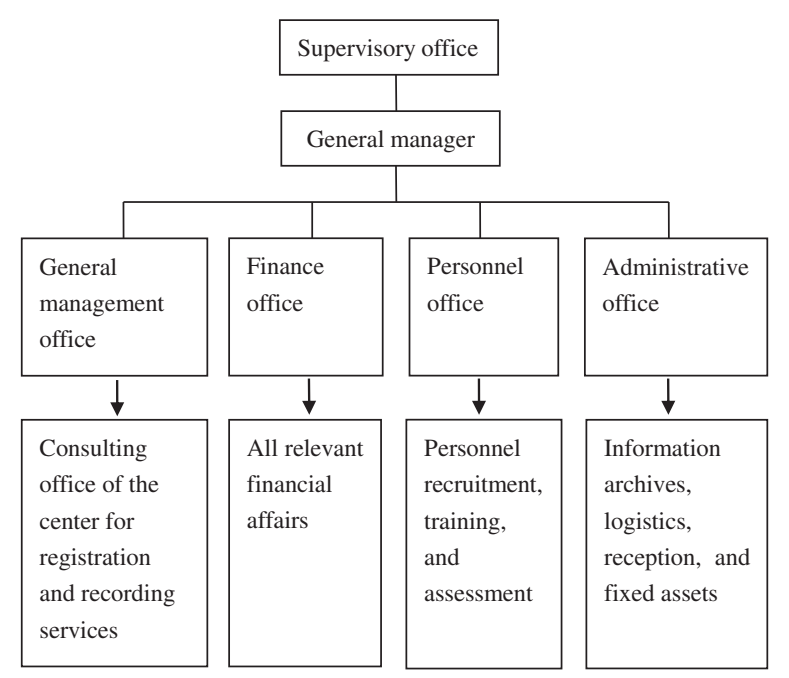

Fig. 3 Actual administrative hierarchy of the service center

service center including information consultation for both the demand and supply sides of the private lending and transaction registration services. The administrative office is responsible for transaction file management. The finance and personnel office is in charge of finance and personnel issues in the service center. Our fieldwork shows that the supervisory office set by the district government has significant impact on the administrative structure of the center and also on the actual operation of the center. These impacts are indicated by the interaction between the supervisor and general manager and the relationship between the general office and administrative office.

First, regarding the interactions between the supervisory office and the general manager, the supervisory office has direct intervention in the decision-making process at the center, which undermines the autocracy of the general manager. The center often deals with important issues such as marketing, maintaining relations with banks, and risk prevention and control, which need direct intervention by leadership. Our field observations show that there are two methods of intervention. First is the bottom-up method; that is, the general management office reports information to the general manger and the supervisory office for consideration, and a decision is made by the supervisory office. The second method is top-down; that is, the supervisory office passes decisions regarding the service center made by the district or city government to the general manager and the general office.

Second, regarding the relationship between the supervisory office and the general management office, the supervisory office has direct control over the daily functioning of the management office. The management office is in charge of the entire transaction in private lending, which includes information dissemination and registration of transactions, regulating intermediaries and ancillary services, and the interrelationship between the center and intermediary agencies. Our field observations showed that the general management office regularly reports to the supervisory office about its daily work; the supervisory office comments on the work, and the general management office adjusts their day-to-day work accordingly.

Third, regarding the relationship between the supervisory office and the administrative office, the supervisory office supervises and actually controls information 
management at the service center. In private lending transactions, a large amount of transaction data is generated, and maintaining the security of the information is a vital job of the service center. The supervisory office controls the information flow in two ways: one is the use of information technology to limit access to the data by departments of the center; the other is to supervise the management of administrative office on the hard copies of all transaction records.

In conclusion, the supervisory office holds actual control rights over the center via direct intervention in the decision-making procedure and in the daily work of the general management office and general administrative office. In addition, the supervisory office reduces the information asymmetry between the private enterprise and the local government. In this sense, the local government holds the actual control rights over the operation of the center. It is in fact the actual producer of the public goods discussed here. The corporate production of public goods is more of a symbolic organizational form.

\section{Conclusion and discussion}

This study examines an interesting phenomenon that appeared during the folk financial reform in 2012; that is, the government authorizes corporations to produce innovative public goods, but the corporation presents several organizational characteristics of government departments in production. Existing theories do not provide satisfying explanations for this phenomenon. We thus used the theoretical perspective of organizational sociology to develop a new analytical framework. Our research shows that production of innovative public goods is subject to uncertainties in the technical or institutional environment; one important strategy of the local government for reducing possible loss due to this uncertainty is to select an organizational form that can reduce the risk in production and to grasp the actual control rights of the production. Applying this analytical framework to the Wenzhou Private Lending Service Center, we discovered that the local government, in response to both technical and institutional risks, chose a mixed organizational form for the service center and obtained the actual control rights of its operation.

For the case studied here, we proposed a sociological explanation that differs from economic explanations. Transaction cost economics and the new property rights explanation emphasize the efficiency mechanism in the bilateral trade relations between the government and the private sector. However, this article argues that the external institutional environment also has a major impact on the government's behavior. Specifically, the risk-averse mechanism that we have revealed from the perspective of organizational sociology attaches great importance to external environmental constraints and the government's strategic behavior. It should be noted that we do not disagree with efficiency explanations of economics but rather provide a sociological explanation to this kind of question as a supplement. Therefore, when the local government selects the private sector to produce public goods, it is likely to be based on efficiency considerations of the modes of supply and is equally likely to be a reaction of organizational form selection to constraints from the external environment. In this sense, in order to discover the real logic behind a governmental behavior, not only does the interaction between government and private sector have to be examined but also the external environment that could 
influence governmental behavior. Especially for research on innovative public goods production, the behavior logic of the local government in an uncertain environment that this article has revealed is worth further attention.

Although this article focuses on the production of innovative public goods, the findings of this article may infer similar organizational phenomena in other sectors. For example, the Red Hat enterprises discussed in organizational sociology bear some similarities to the case studied here. The former refers to private enterprises that wear the "hat of government" and the latter refers to the government putting on the "shell of enterprise." Governmental penetration into business associations (Liu 2012) is another example similar to the case studied in this article. Government-led nongovernment organizations (Tian 2004) are another similar example. Both refer to a carefully selected organizational form that allows the government to maintain actual control rights to organizational operation.

Why is this a common practice in China? What are the similarities and differences between these common practices? In essence, it is a practice of utilizing a nominal organizational form to achieve certain organizational aims; the actual operation of the organization is different from its nominal form. It involves interactions between organizations, as well as interactions between organizations and the external environment. The new institutionalism of organizational sociology uses the concept of an organization's legitimacy (Meyer and Rowan 1977; DiMaggio and Powell 1983; Suchman 1995; Zhou 2003) to explain such an organizational phenomenon. It argues that in reaction to uncertainty in the environment, an organization tends to choose an accepted organizational form in order to achieve organizational aims. This theory can explain the Red Hat strategy but cannot fully explain the production of public goods by private enterprise. This is because this approach assumes that a stable institution exists; however, in the case studied here, no stable institutions exist, and the government has to make decisions in such a context. In this sense, the governmental choice studied here is not based on an evaluation of which organizational form is acceptable but rather on the degree of acceptance of organizational forms. This selection process itself bears certain risks.

More importantly, the phenomenon discussed in this article may have different characteristics; it may have a hybrid organizational form or a multiple organizational form. In fact, the hybrid organizational form is common in other sectors. For example, Shen and Sun (2007) study the organizational form of the China Youth Foundation and discover that the hybrid organizational form has dual roles of "dual institutional space" and "risky institutional environment." It should be noted that the organizational form discussed in organizational sociology is different from the organizational form studied in this article; the former emphasizes the differences between organizational characteristics and internal operation, but the latter focuses on the multiple dimensions of an organizational characteristic. In addition, the former discusses the selection of organizational form in a single-dimensional environment, but the latter discusses the selection of organizational form in a multidimensional environment. The theory of selection of organizational form in a single-dimensional environment cannot explain the selection of organizational form in a multidimensional environment.

This article provides alternative explanations to the hybrid organizational form; that is, this type of organizational form is the result of constraints from a multidimensional 
environment, and the implementation of this organizational form is subject to a rational choice from comparing different organizational forms. The actual operation of the organization shows interactions between various organizations. This analytical model may direct us to another interesting question, that is, the multidimensional environment of certain organizations. Why do different organizational forms have different competitive advantages when reducing pressure from the external environment? What is the mechanism for an organization to reduce pressure from the external environment? Can a legitimate mechanism explain complex organizational forms in a multidimensional environment? How can different organizations with different organizational aims create hybrid organizational forms via interactions? How can the actual operation of the hybrid organizational form resolve conflicts between different interest parties? These questions await further exploration.

\section{Endnotes}

${ }^{1}$ Erdos, Changsha, Ninghai, Zibo, Changzhi, and other cities in China have similar organizations.

${ }^{2}$ According to Samuelson's definition (1954), public goods are a nonexclusive and noncompetitive consumption. The government regulates the production, distribution, and management of public goods.

${ }^{3}$ In the production of public goods, governments at different levels face different risk constraints. This article focuses on grassroots-level governments.

${ }^{4}$ Thompson's (1967) analysis of the buffering layer between the technical core and external environment is instructive, but he focuses on the influence of the technical environment on the internal structure of an organization. He does not discuss the institutional environment, and thus, his theory cannot explain the case studied by this article-the service center shows complex characteristics, and these characteristics are linked with the actual internal operation of the service center. DiMaggio and Powell (1983) emphasize that isomorphism can reduce the pressure from uncertainty, but it cannot provide satisfying explanations to the case studied here. Because the private lending practice is a newly established institution, it cannot borrow from previous institutions to regulate its function. Many local governments in this case may imitate Wenzhou, but as a pioneer, Wenzhou cannot imitate anyone. In addition, the isomorphism existing in this case is due to a similar external environment faced by local governments, because the innovation practice of Wenzhou government has not been proved to be successful yet.

${ }^{5}$ The term organizational form bears a similar meaning in the rest of this article.

${ }^{6}$ This is the draft for the "Wenzhou Private Lending Registration Service Center regulation methods (trial)" (Wenlu government office 2012 [285] document).

7"P2P" refers to peer to peer.

${ }^{8}$ The proposal for the establishment of the service center states that the $\mathrm{Q}$ city government can set up a public-service organization, or civil-association form of a service center, or the city finance bureau and city-owned enterprises can establish a "state-owned enterprise." If there are qualified private enterprises that are interested in participating, they can found a "private enterprise" to run the service center. The organizational form of the service center has to consider market confidence, government regulations, and potential liability for the government. A public-service organization type 
of service center has higher market confidence but has lower risk-control capability. The second method is to set up an industrial association to provide business consultation, and the association will manage the operations of the service center. Given the current development of the consulting industry in Q city, the utilization of an association for a service center has certain difficulties. A feasible plan is to set up an SOE, which has high confidence from relevant parties. The other method is to set up a private enterprise, using the market mechanism and the government's policy support to operate the service center. If the above plan is adopted, a special name should be given to the service center.

${ }^{9}$ The official Web site of the service center (http://www.wzmjjddj.com/) has all the information about names, property, aims, and services of the service center. The Wenzhou Private Lending Registration Service Center is a limited enterprise that is approved by city and district governments and is registered with Lucheng's Bureau of Industry and Commerce. The registration asset was 6 million yuan, and its services include information registration, information consultation, information publication, and a financing docking service; it mainly aims to provide registration service for private lending transactions. The service center is part of the pilot reform for Wenzhou's financial system reform, with an aim to regulating the private lending market in Wenzhou, bringing private money to the economy, and SME entrepreneurship using legal procedures to reduce the financial risk in civil lending and to explore a possible way of developing a healthy private lending sector.

${ }^{10}$ The operation mechanism of the service center is as follows. The creditor or debtor registers their demand at the service center and selects intermediary agencies at the center. The service center sends these inquiries to selected intermediary agencies. When both parties agree on the lending contract, the transaction between creditor and debtor will be registered with the center. The intermediary agency can provide customer service for the creditor such as payment reminder services. When the contract is due, the service center assesses and records the credibility of the debtor.

${ }^{11}$ The 1998 statement "on suppression of illegal financial institutions and illegal financial activities" by the State Council and the 2003 "regulatory methods for banking industry" authorize the regulation of civil lending to the People's Bank of China and the China Bank Regulatory Committee and require local governments to provide support. However, they do not specify the relations between the two parties in regulating the financial sector nor do they specify the content for supervision. Hence, in reality, no real supervision or regulation has been carried out on many civil lending activities (Chen 2008).

${ }^{12}$ This was approved at the 12th People's Congress Standing Committee meeting in Zhenjiang province, November 22, 2013, and officially introduced on March 1, 2014. Articles 4,5 , and 8 provide detailed definition about the responsibilities and roles of the service center.

${ }^{13}$ According to the 2nd article of the "P.R. China's law on personal income tax," interest should be counted as personal income and thus tax must be paid on it; the 3rd article of the same law states that the tax rate for interest is $20 \%$. The 10th article in the "State Administration of Taxation on sales tax questions and answers (one)" (the ministry of taxation [1995] number 156 document) states that regardless of the properties of 
the financial institutions, when loaning activities are involved interest on loans must be taxed at a $5 \%$ rate.

${ }^{14}$ For example, the legal definition is unclear for the two concepts "illegal absorbing of public deposit" and "disguising the absorbing of public deposit." Although some administrative regulations give clear distinctions between the two concepts, they still do not provide a clear definition for the concept "public deposit."

${ }^{15}$ It should be noted that the government tends to not mention the supervisory office in official announcements. This is because it will cause more liabilities for the government if the public is aware of the government's direct intervention in the service center.

Competing interests

The authors declare that they have no competing interests.

\section{Authors' contributions}

JX carried out the case study and drafted the manuscript. XZ provided research funding support, added some important empirical materials, and participated in the manuscript drafting and modification. Both authors read and approved the final manuscript.

\section{Acknowledgements}

We appreciate the support from the National Natural Science Foundation of China (NSFC) projects for young academics (71203195), the National Social Science Fund general project (11BSH040), Research Institute for Wenzhounese Economy (12JDWZ01Z), and Wenzhou Academy of Financial Research (ZB12012). Special thanks also go to Xiangmei Zhang, Hui Jiang, Zhubo Lin, Yuesheng Li, Zhiqian Xu, Deming Zheng, Peng Liu, Wei Shao, and Mingheng Chen for their help with research materials. We acknowledge the comments from Chengshu Gao, Gang Zhao, Shiding Liu, Zeqi Qiu, Zhenghan Cao, Jing Zhang, Kai Tian, Ming Ren, Xiaochun Huang, Wei Zhao, Xuefei Lin, Jin Huang, Jiawei Pang, Huiqiang Zhang, Jianzuo Zhang, Yuhang Zhai, Yuanxiong Tang, Lei Di, Qi Xu, and Jianning Yu. Special thanks also go to the two anonymous reviewers for this article. The authors of this article take all responsibility.

\section{Author details}

${ }^{1}$ Institute of Sociology, Chinese Academy of Social Sciences, No. 5, Jianguomennei Dajie, 100732 Beijing, China.

${ }^{2}$ School of Public Affairs, Zhejiang University, 388\# Yuhangtang Road, Xihu District, Hangzhou, Zhejiang Province 310058, China.

Received: 26 September 2015 Accepted: 9 November 2015

Published online: 26 November 2015

\section{References}

Aghion, Philippe, and Jean Tirole. 1995. Some implications of growth for organizational form and ownership structure. European Economic Review 39: 440-455.

Aghion, Philippe, and Jean Tirole. 1997. Formal and real authority in organizations. The Journal of Political Economy 105: 1-29.

Cai, Yongshun. 2008. Power structure and regime resilience: contentious politics in China. British Journal of Political Science 38: 411-432.

Cao, Zhenghan. 2011. "The vertically decentralized authoritarianism and the mechanisms of political stability in China", in Chinese. Sociological Studies 1: 1-40.

Cao, Zhenghan, and Biliang Luo. 2013. "Political risk of centralization and the vertical separation of powers: reform of contemporary social management system from a historical perspective.", in Chinese. South China Journal of Economics 2: 1-11.

Cao, Zhenghan, and Jie Zhou. 2013. "Social risks and decentralization: the reason of decentralized supervision on national food safety in China.", in Chinese. Sociological Studies 1: 182-205.

Chandler, Alfred D. 1962. Strategy and structure: chapters in the history of the American industrial enterprise. Cambridge: MIT Press.

Chen, Rong. 2008. The reconstruction of regulation on civil finance in China (unpublished doctoral dissertation), in Chinese Chongqing: Southwest University of Political Science and Law.

Coase, Ronald H. 1937. The nature of the firm. Economica New Series 4: 386-405.

Coase, Ronald H. 1974. The lighthouse in economics. Journal of Law and Economics 17: 357-376.

Demsetz, Harold. 1970. The private production of public goods. Journal of Law and Economics 13: 293-306.

DiMaggio, Paul J., and Walter W. Powell. 1983. The iron cage revisited: institutional isomorphism and collective rationality in organizational fields. American Sociological Review 48: 147-160.

Fei, Xiaotong. 2009. China's gentry, Translated by Xudong Zhao and Qin Zhijie. Beijing: Joint Publishing.

Goldin, Kenneth D. 1977. Equal access vs. selective access: a critique of public goods theory. Public Choice 29: 53-71.

Grossman, Sanford, and Oliver Hart. 1986. The costs and benefits of ownership: a theory of vertical and lateral ownership. Journal of Political Economy 94: 691-719. 
Han, Fuguo. 2004. Market, organization and state: an analysis of an organization ACFIC's dual-agent function in Chinese institutional game (unpublished doctoral dissertation). Shanghai: Fudan University.

Hannan, Michael T., and John Freeman. 1977. The population ecology of organizations. American Journal of Sociology 82: 929-964.

Hannan, Michael T., and John Freeman. 1986. Where do organizational forms come from? Sociological Forum 1: 50-72. Hart, Oliver, and John Moore. 1990. Property rights and the nature of the firm. Journal of Political Economy 98: 1119-1158.

Hart, O., A. Shleifer, and R.W. Vishny. 1997. The proper scope of government: theory and an application to prisons. The Quarterly Journal of Economics 112: 1127-1161.

Liu, Shiding. 2012. The right to organize and the interference of government in the use of private property: a case study of the relationship between government and chamber of commerce. In National construction and government behavior. Beijing: China Social Science Press.

Lv, Fang. 2013. "Situational analysis of governance: local government behavior in risk constraint.", in Chinese. Sociological Studies 2: 98-125.

Mao, Shoulong. 2005. "Blame-taking and resigning, accountability system, and the changing method of ruling country.", in Chinese. Zhejiang Academic Journal 1: 45-49.

Maskin, Eric, Yingyi Qian, and Chenggang Xu. 2000. Incentives, information, and organizational form. The Review of Economic Studies 67: 359-378.

Meyer, John W., and Brian Rowan. 1977. Institutionalized organizations: formal structure as myth and ceremony. American Journal of Sociology 83: 340-363.

Milgrom, Paul, and John Roberts. 1992. Economics, organization and management. Englewood Cliffs: Prentice Hall.

Musgrave, Richard A. 1959. The theory of public finance: a study in public economy. New York: McGraw-Hill.

Ostrom, Vincent, Charles M. Tiebout, and Robert Warren. 1961. The organization of government in metropolitan areas: a theoretical inquiry. The American Political Science Review 55: 831-842.

Powell, Water W. 1991. Expanding the scope of institutional analysis. In The new institutionalism in organizational analysis, ed. Walter W. Powell and Paul J. DiMaggio, 183-203. Chicago: University of Chicago Press.

Qian, Yingyi, Gérard Roland, and Chenggang Xu. 2006. Coordination and experimentation in M-form and U-form organizations. Journal of Political Economy 114: 366-402.

Qu, Jingdong, Feizhou Zhou, and Xing Ying. 2009. "From macromanagement to micromanagement-reflections on thirty years of reform from the sociological perspective.", in Chinese. China Social Science 6: 104-127.

Romanelli, Elaine. 1991. The evolution of new organizational forms. Annual Review of Sociology 17: 79-103.

Rong, Jingben, et al. 1998. Transition from pressure-type system to democratic cooperation system, in Chinese. Beijing: Central Compilation \& Translation Press.

Ruef, Martin. 2000. The emergence of organizational forms: a community ecology approach. American Journal of Sociology 106: 658-714.

Samuelson, Paul A. 1954. The pure theory of public expenditure. The Review of Economics and Statistics 36: 387-389.

Savas, E.S. 2002. Privatization and public-private partnerships, translated by Zhireng Zhou, et al. Beijing: China Renmin University Press.

Scott, W. Richard. 1991. Unpacking institutional arguments. In The new institutionalism in organizational analysis, ed. Walter W. Powell and Paul J. DiMaggio, 164-182. Chicago: University of Chicago Press.

Scott, W. Richard, and John W. Meyer. 1991. The organization of societal sectors: propositions and early evidence. In The new institutionalism in organizational analysis, ed. Walter W. Powell and Paul J. DiMaggio, 108-140. Chicago: University of Chicago Press.

Shen, Yuan, and Wusan Sun. 2007. Same form and different contents of institutions and the development of social groups: an analysis of china youth development foundation and its diplomatic activities, in Chinese. In Market, class and society, ed. Yuan Sheng, 301-324. Beijing: Social Sciences Academics Press.

Spence, Michael. 1973. Job market signaling. The Quarterly Journal of Economics 87: 355-374.

Suchman, Mark C. 1995. Managing legitimacy: strategic and institutional approaches. The Academy of Management Review 20: 571-610.

Thompson, James D. 1967. Organizations in action: social science bases of administrative theory. New York: McGraw-Hill.

Tian, Kai. 2004. "The decoupling of organization: the organizational operation under non-coordinate constraint-a framework to study the relationship between China's charity organizations and government.", in Chinese. Sociological Studies 4: 64-75.

Wang, Hansheng, and Yige Wang. 2009. "Target management responsibility system: the practical logic of local party-state in Rural China.", in Chinese. Sociological Studies 2: 61-92.

Williamson, Oliver E. 1975. Markets and hierarchies: analysis and antitrust implications. New York: Free Press.

Williamson, Oliver E. 1979. Transaction-cost economics: the governance of contractual relations. Journal of Law and Economics 22: 233-261.

Williamson, Oliver E. 1985. The economic institutions of capitalism. New York: Free Press.

Zhang, Jing. 2001. "State building and rural autonomous units - problems and review.", in Chinese. Open Times 9: 5-13.

Zhang, Xiang. 2010. "Government credit as signal: information mechanism of private depository institution in Wenzhou and Taizhou after reform.", in Chinese. Sociological Studies 6: 116-148.

Zhou, Xueguang. 2003. "Ten lectures on organizational sociology.", in Chinese. Beijing: Social Sciences Academic Press.

Zhou, Li'an. 2004. "The incentive and cooperation of government officials in the political tournaments: an interpretation of the prolonged local protectionism and duplicative investment in China.", in Chinese. Economic Research Journal 6: 33-40.

Zhou, X. 2005. "Inverted soft budget constraint: extra budgetary resource-seeking in local governments", in Chinese. Social Sciences in China 2: 132-143.

Zhou, Li'an. 2007. "Governing China's local officials: an analysis of promotion tournament model.", in Chinese. Economic Research Journal 7: 36-50.

Zhou, Xueguang, and Hong Lian. 2012. "Modes of governance in the Chinese Bureaucracy: a 'control rights' theory.", in Chinese. Sociological Studies 5: 69-93. 